\title{
Preparation and Evaluation of Matrix Type Transdermal Patches of Domperidone Maleate: in vitro and ex vivo Characterization
}

\author{
Suddala Shirisha1*, Gomathi Joshi², Sunit Kumar Sahoo', Yamsani Madhusudan Rao² \\ ${ }^{1}$ UDPS, Utkal University, Vani Vihar, Bhubaneswar, Orissa. INDIA. \\ ${ }^{2}$ Vaagdevi Institute of Pharmaceutical Sciences, Bollikunta, Warangal, Telangana, INDIA.
}

\begin{abstract}
Objective: Domperidone Maleate is a dopamine - receptor $\left(D_{2}\right)$ antagonist, widely used in the treatment of motion sickness and used as an antiemetic. The bioavailability of domperidone maleate when administered orally is low due to the first pass metabolism in liver, drug delivery through transdermal drug delivery has the ability to deliver the drug directly to systemic circulation by passing the liver and hence increase in bioavailability of the drug. The main aim of this investigation is to develop and evaluate matrix type transdermal drug delivery systems of domperidone maleate. Methods: The matrix type transdermal patches of Domperidone Maleate were prepared by solvent evaporation technique. The tensile strength and elongation break, in vitro drug release, in vitro drug permeation and Ex vivo permeation through rat abdominal skin were studied. The physicochemical interaction between domperidone maleate and polymer were examined by Fourier Transform Infrared Spectroscopy (FTIR). Results: All the formulations showed satisfactory physicochemical and mechanical characteristics. The optimized formulation F5 (drug: polymer ratio is $1: 12.5$ and $5 \% \mathrm{v} / \mathrm{w}$ eucalyptus oil) showed maximum cumulative percentage of drug release $\left(1832.16 \pm 60.14 \mu \mathrm{g} / \mathrm{cm}^{2}\right)$, permeation $\left(650.36 \pm 29.6 \mu \mathrm{g} / \mathrm{cm}^{2}\right)$ in $10 \mathrm{hrs}$. Flux $\left(20.462 \mu \mathrm{g} / \mathrm{hr} / \mathrm{cm}^{2}\right)$ and permeation coefficient of $0.204 \times 10^{-2} \mathrm{~cm} / \mathrm{hr}$. Values of tensile strength $\left(2.66 \pm 0.0026 \mathrm{~kg} / \mathrm{mm}^{2}\right)$ and elongation at break $(16.57 \pm 0.26$ $\% \mathrm{~mm}^{2}$ ) revealed that formulation F5 was strong but not brittle. FTIR studies showed no evidence of interaction between the drug and polymers. Conclusion: Domperidone maleate matrix type transdermal therapeutic systems could be prepared with the required flux and suitable mechanical properties.
\end{abstract}

Key words: Domperidone Maleate, Matrix type transdermal patches, Permeation enhancer, in vitro release, ex vivo permeation, Flux.

\section{INTRODUCTION}

Advances in new research are resulting in a large number of drugs that are being delivered transdermally. Transdermal drug delivery systems are desirable because of the advantages over the other routes of drug delivery. This system provides convenient, pain less, self-administration, eliminate frequent dosing of the drug with short half-life can be delivered and generally they are improving patient compliance. ${ }^{1-2}$ For potent drugs having extensive first pass metabolism this is preferable delivery system. It also has additional advantage that dosage forms can be removed in emergency (adverse/ side effect) or when action is to be stopped. Intensive research has reported that transdermal drug delivery is a probable mode of delivery for lipophilic drugs in systemic circulation. ${ }^{3-5}$

Nausea and vomiting are prominent, due to direct stimulation of CTZ by the cytotoxic drugs as well as products of emetic impulses and mediators from upper gastro intestinal tract. Domperidone maleate is a dopamine receptor antagonist, widely used in nausea
Submission Date: 07-01-2017; Revision Date: 23-03-2017; Accepted Date: 13-07-2017

DOI: $10.5530 /$ ijper.51.4.80 Correspondence: Suddala Shirisha, UDPS, Utkal University, Vani Vihar, Bhubaneswar, Orissa, INDIA.

Mobile no- 91-8121223076

E-mail: suddala.shirisha@ gmail.com,

sahoosunitkumar@gmail.com

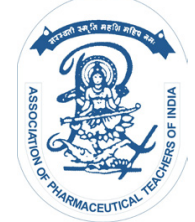

www.ijper.org 
and vomiting. In humans, after intra muscular injection of domperidone peak plasma concentration occurs within 10-30min, after oral administration. It has been reported that, after oral administration domperidone is rapidly absorbed, but it shows poor bioavailability (15\%) due to hepatic first pass metabolism. From above reasons, physicochemical properties like molecular weight $425.9 \mathrm{~g} / \mathrm{mol}$, dose $10 \mathrm{mg}$ and pharmacokinetic property like absolute bioavailability 10-20\%, log P 3.11, domperidone was considered to be a suitable drug candidate for transdermal delivery. ${ }^{6}$

However, the highly organized structure of the skin is stratum corneum forms a formidable layer for drug permeation. It should be modified if poorly permeable drugs are to be administered. ${ }^{7-8}$ Two major strategies to increase rate of permeation through skin include physical methods (electroporation, iontophoresis, microneedles, and sonophoresis) and chemical method including permeation enhancers like solvents, fatty acids, surfactants and terpenes. ${ }^{9-11}$ Terpenes are naturally occurring volatile oils and appear to be clinically acceptable permeation enhancers. Different types of terpenes have been shown to increase the permeation of a number of drugs. In the present research, menthol and eucalyptus oil were used as permeation enhancers. ${ }^{12-13}$ The objective of present research was development of matrix type transdermal patches of domperidone maleate and to evaluate physicochemical, mechanical properties, in vitro drug release, in vitro permeation and Ex vivo permeation through rat abdominal skin.

\section{MATERIAL AND METHODS}

\section{Materials}

Domperidone Maleate was gifted by Merk limited, Mumbai and Hydroxy propyl methyl cellulose (HPMC E15), Poly ethylene glycol (PEG-400), Menthol, Eucalyptus oil were obtained from S.D. fine chemicals.

\section{Development of matrix type transdermal system}

Matrix type transdermal patches were prepared by using solvent casting method with HPMC E15 as a polymer and poly ethylene glycol as a plasticizer. Weighed quantity of polymer dissolved in $25 \mathrm{ml}$ of solvent mixture 1:1 ratio of (Methanol: Dichloromethane) allowed for swelling for about 6 hours, polyethylene glycol and drug were dissolved in solvent mixture and added to the polymeric solution. Measured quantity of menthol and eucalyptus oil $(5 \% \mathrm{v} / \mathrm{w})$ were added as a permeation enhancer. This was set aside for 2 hrs to exclude entrapped air, then transferred to a petriplate, and dried at room temperature. ${ }^{14}$ The developed matrix type patches were carefully removed
Table 1: Composition of transdermal patches

\begin{tabular}{|c|c|c|c|c|c|}
\hline $\begin{array}{c}\text { Formulation/ } \\
\text { Ingredients }\end{array}$ & F1 & F2 & F3 & F4 & F5 \\
\hline $\begin{array}{c}\text { Domperidone } \\
\text { Maleate(mg) }\end{array}$ & 159 & 159 & 159 & 159 & 159 \\
\hline HPMC E15 (mg) & 1590 & 1987.5 & 2385 & 1987.5 & 1987.5 \\
\hline PEG 400( $\boldsymbol{\mu l})$ & 270.3 & 337.85 & 405.45 & 337.85 & 337.85 \\
\hline Methanol(ml) & 12.5 & 12.5 & 12.5 & 12.5 & 12.5 \\
\hline DCM(ml) & 12.5 & 12.5 & 12.5 & 12.5 & 12.5 \\
\hline Menthol $(\boldsymbol{\mu l})$ & - & - & - & 175.5 & - \\
\hline Eucalyptus $(\boldsymbol{\mu l})$ & - & - & - & - & 167.2 \\
\hline
\end{tabular}

and cut into size $4 \mathrm{~cm}^{2}$, and stored in desiccator. The prepared patches were subjected to evaluation process. The composition of patches is shown in Table 1.

\section{Evaluation physicochemical properties:}

From each formulation six patches were weighed individually and average weight was calculated. The thickness of the patch was measured at six different points of patch using screw gauze. Patches from each formulation $(\mathrm{n}=3)$ of $4 \mathrm{~cm}^{2}$ were cut into pieces and weighed. The pieces were taken into $100 \mathrm{ml}$ volumetric flask, allowed to dissolve in $2 \mathrm{ml} \mathrm{DMF}$ (dimethyl formamide) and made up to $100 \mathrm{~mL}$ with $0.1 \mathrm{~N}$ hydrochloric acid. The above solution was filtered using $0.45 \mu \mathrm{m}$ membrane filter and the drug content was analyzed using UV-visible spectrophotometer at $284 \mathrm{~nm}$. Folding endurance of the patch was determined manually by repeatedly folding a small strip of the medicated patch at the same place until broken. The number of times the strip could be folded at the same place without breaking gave the folding endurance. $^{15}$

\section{Moisture absorption study}

Accurately weighed patches were placed in a desiccator containing $100 \mathrm{ml}$ of saturated aluminum chloride solution $(79.5 \% \mathrm{RH})$. After three days the patches were taken out from desiccator and weighed. The percentage of moisture absorption was calculated as the difference between the final and initial weight with respect to the initial weight. ${ }^{16}$

$$
\% \text { Moisture absorbed }=\frac{\begin{array}{l}
\text { Final weight }- \\
\text { Initial weight }
\end{array}}{\text { Initial weight }} \times 100
$$

\section{Moisture content determination}

Accurately weighed patches were placed in a desiccator containing calcium chloride solution at $40^{\circ} \mathrm{C}$ for 24 hrs. The final weight patches were noted until there was no 
further increase in weight of patches. The percentage of moisture content was calculated using following formula. ${ }^{16}$

$$
\% \text { Moisture Content }=\frac{\begin{array}{l}
\text { Initial weight } \\
\text { Final weight }
\end{array}}{\text { Initial weight }} \times 100
$$

\section{Water vapor transmission rate studies (WVTR)}

WVTR studies were performed according to method described by Kusum Devi et al. ${ }^{17}$ Use glass vials of equal diameter as transmission cells. These transmission cells were washed thoroughly and dried in oven. About $1 \mathrm{gm}$ anhydrous calcium chloride was placed in the cells and the respective transdermal film was fixed over the brim. The cells were accurately weighed and kept in a closed desiccator containing saturated solution of potassium chloride to maintain a relative humidity of $84 \%$. The cells were taken out and weighed after storage. The amount of water vapor transmitted was found using following formula:

$$
\text { Water vapor transmission rate }=\frac{(\text { Final weight }-}{\text { Initial weight }}
$$

WVTR is expressed as the number of grams of moisture gained $/ \mathrm{hr} / \mathrm{cm}^{2}$.

\section{Measurement of mechanical properties}

Mechanical properties of the films were evaluated using a microprocessor based advanced force gauze (Ultra Test, Mecmesin, UK) equipped with a $25 \mathrm{~kg}$ load cell. Film strip with dimensions $60 \times 10 \mathrm{~mm}$ and free from air bubbles or physical imperfections were pulled the strips to a distance held between two clamps positioned at a distance of $3 \mathrm{~cm}$. During measurement, the top clamp at a rate of $2 \mathrm{~mm} / \mathrm{s}$ till the film broke. The force and elongation were measured, when the film broke. The mechanical properties were calculated according to the following formulae. Measurements were run in four replicates for each formulation. ${ }^{18}$

$$
\begin{aligned}
\text { Tensile strength }\left(\mathrm{Kg} / \mathrm{mm}^{2}\right)= & \frac{\text { Force at break }(\mathrm{kg})}{\text { Initial cross sec tion }} \\
& \text { area of the sample }\left(\mathrm{mm}^{2}\right)
\end{aligned}
$$

$$
\begin{aligned}
\text { Elongation at break }\left(\% \mathrm{~mm}^{-2}\right)= & \frac{\text { Increase in length }(\mathrm{mm})}{\text { Original length }(\mathrm{mm}) \times} \times 100 \\
& \text { Cross sectional area }\left(\mathrm{mm}^{2}\right)
\end{aligned}
$$

$\operatorname{EM}\left(\mathrm{Kg} / \mathrm{mm}^{2}\right)=\frac{\text { Force at corresponding strain }(\mathrm{Kg})}{\text { Cross sec tional area }\left(\mathrm{mm}^{2}\right)} \times \frac{1}{\text { Corresponding strain }}$

Strain $=\frac{\text { Tensile strength }}{\text { Elastic modulus }}$

The tensile testing gives an indication of the strength and elasticity of the film, reflected by the parameters, tensile strength (TS) and elongation at break (E/B). A soft and weak polymer is characterized by a low TS, and low $\mathrm{E} / \mathrm{B}$; a soft and tough polymer is characterized by a moderate TS, and high E/B; where as a hard and tough polymer is characterized by a high TS, and E/B. Another parameter strain value indicates that the film is strong and elastic. Hence, it is suggested that a suitable transdermal film should have a relatively high TS, E/B.

\section{In vitro drug release studies}

In vitro release studies were carried out using Franz diffusion cell. The transdermal patch was kept in the donor compartment and it was separated from the receptor compartment by dialysis membrane (Hi media M.W. cut off 5000). The donor and receptor compartment were held together using clamp. The receiver compartment contained $20 \mathrm{ml}$ of PBS of $\mathrm{pH} 7.4$ containing $20 \% \mathrm{v} / \mathrm{v}$ of PEG-400, stirred at $500 \mathrm{rpm}$ and temperature was maintained at $37 \pm 0.5^{\circ} \mathrm{C}$. One $\mathrm{ml}$ of samples were withdrawn at pre-determined time intervals and replaced with an equal volume of fresh medium. The drug content in the samples was determined by UV/ visible spectrophotometer at $284 \mathrm{~nm}$. Cumulative amount of the drug released were calculated and plotted against time.

\section{Ex vivo permeation studies Preparation of rat abdominal skin}

Albino rats having weight 150-200 gm were sacrificed using anesthetic ether. The hair of test animals was carefully trimmed short $(<2 \mathrm{~mm})$ with a pair of scissors and the full thickness skin was removed from the abdominal region. Prepared the epidermis surgically by heat separation technique, involving soaking the entire abdominal skin in water at $60^{\circ} \mathrm{c}$ for $45 \mathrm{sec}$, followed by careful removal of the epidermis. The epidermis was washed with water and used for Ex vivo skin permeability studies.

For Ex vivo permeation studies the skin was mounted between the two compartments of the franz diffusion cell with stratum corneum facing the donor compartment. The stratum corneum side of the skin was kept in intimate contact with the release surface of the TDDS under test. A dialysis membrane (Hi Media, M.W. cutoff 
5000) was placed over the patch, in order to secure it tightly in the way that it will not get dislodged from the skin. The receiver phase contained $20 \mathrm{ml}$ PBS of $\mathrm{pH} 7.4$ containing 20\% v/v PEG 400 which was stirred at $500 \mathrm{rpm}$ on a magnetic stirrer and the whole assembly was kept at $37 \pm 0.5^{\circ} \mathrm{C}$. Samples of $1 \mathrm{ml}$ were withdrawn at pre-determined time intervals up to $10 \mathrm{hrs}$, the volume was replenished with an equal volume of fresh medium and analyzed by UV spectrophotometer. Cumulative amounts of drug permeated in $\mu \mathrm{g} / \mathrm{cm}^{2}$ were plotted against time and drug flux $\left(\mu \mathrm{g} / \mathrm{cm}^{2} / \mathrm{hr}\right)$ at steady state was calculated by dividing the slope of the linear portion of the curve by the area of the exposed skin surface $\left(3.14 \mathrm{~cm}^{2}\right)$ and the permeability coefficient was deduced by dividing the flux by initial drug load. ${ }^{19-20}$

\section{Drug-polymer interaction studies}

Fourier transform infrared spectroscopy studies were carried out to determine possible interaction between drug and polymer utilizing the $\mathrm{KBr}$ pellet method. (PerkinElmer FT-IR)

\section{RESULTS AND DISCUSSION}

\section{Weight, thickness variation, drug content and folding endurance}

The physicochemical characteristics like weight, thickness variation, drug content and folding endurance of the transdermal patches are shown Table 2. The weight range of the patches were from $150.3 \pm 1.84$ to $159.6 \pm 0.22 \mathrm{mg}$. In formulations F1 to F3 the weight of the patches was different and F2, F4 and F5 the weight is almost same. Thickness ranges from $0.40 \pm 0.75$ to $0.58 \pm 0.98 \mathrm{~mm}$. The weight and thickness increases with increasing HPMC E15 concentration in patches. The results showed that the transdermal films were uniform, as it was evidenced by RSD value, which were less than 6. Good uniformity in drug content was observed in all transdermal patches as evidenced by low RSD values. The drug content ranges from $98.56 \pm 0.14$ to 103.48 \pm 0.26 . The folding endurance numbers of HPMC E15 containing patches has in the range of $96 \pm 5.45$ and for the formulations prepared with penetration enhancers were in the range of $104 \pm 2.15$ to $121 \pm 3.64$. The folding endurance number gives the mechanical property of the patches; high folding endurance number indicate that the patches have high mechanical property. The folding endurance number was increased with increasing HPMC E15 content. These results indicated that the patches would not break and would maintain their integrity with general skin folding when applied.

\section{Moisture absorption and moisture content studies}

The results of moisture content and moisture absorption studies were shown in Figure 1. The moisture content in the formulation varied from $4.34 \pm 0.37$ to $5.85 \pm 0.9$. The moisture absorption in the formulations was from $14.13 \pm 0.39 \%$ to $24.76 \pm 1.57 \%$. The results revealed that the moisture absorption and moisture content was found to increase with increasing the concentration of hydrophilic polymer (HPMC E15). The small moisture content in the formulations help them to remain stable and not being a completely dried and brittle film. Again, low moisture absorption protects the patches from microbial contamination.

\section{Mechanical properties}

The results of mechanical properties (tensile strength, elongation at break) were shown in Table 3. The mechanical properties shows the film's strength and elasticity, as it was revealed by the parameters of tensile strength (TS), elastic modulus (EM) and elongation at break (E/B). A low values of TS, EM, and $\mathrm{E} / \mathrm{B}$ indicates polymer is soft and weak; a hard and tough polymer is characterized by high values of TS, EM and E/B. Another important parameter is strain, which has been used as an indicator of the polymer film's overall mechanical quality. ${ }^{21}$ For a suitable transdermal film should have a high tensile strength, elongation at break and strain but a low elastic modulus. Optimized formulation F5 exhibited TS and EM values $\left(2.66 \pm 0.026 \mathrm{~kg} / \mathrm{mm}^{2}\right.$ and $7.18 \pm$ $0.03 \mathrm{~kg} / \mathrm{mm}^{2}$ ). These observations indicate that as the polymer concentration increased the TS and

\begin{tabular}{|c|c|c|c|c|c|}
\hline Formulation & $\begin{array}{c}\text { Weight } \\
\text { variation }^{\mathrm{a}}\end{array}$ & Thickness $^{a}$ & $\begin{array}{c}\text { Folding } \\
\text { endurance }^{b}\end{array}$ & Drug content ${ }^{\mathrm{b}}(\%)$ & $\operatorname{WVTR}^{\mathrm{b}}(\mathrm{g} / \mathrm{cm} 2) \times 10-3$ \\
\hline F1 & $150.3 \pm 1.84$ & $0.43 \pm 0.71$ & $96 \pm 1.54$ & $98.56 \pm 0.14$ & $3.88 \pm 0.07$ \\
\hline F2 & $152.5 \pm 0.15$ & $0.4 \pm 0.75$ & $104 \pm 2.15$ & $109.48 \pm 0.26$ & $4.41 \pm 0.04$ \\
\hline F3 & $159.6 \pm 0.22$ & $0.58 \pm 0.98$ & $121 \pm 1.64$ & $100.98 \pm 0.16$ & $5.78 \pm 0.08$ \\
\hline F4 & $153.6 \pm 0.16$ & $0.42 \pm 0.77$ & $106 \pm 2.16$ & $99.12 \pm 0.28$ & $5.52 \pm 0.05$ \\
\hline F5 & $156 \pm 0.17$ & $0.46 \pm 0.78$ & $108 \pm 2.19$ & $104 \pm 0.17$ & $5.72 \pm 0.06$ \\
\hline
\end{tabular}

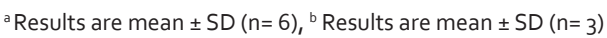




\begin{tabular}{|c|c|c|c|c|}
\hline Formulation & $\begin{array}{l}\text { Tensile strength } \\
\left(\mathbf{k g} / \mathrm{mm}^{2}\right)\end{array}$ & $\begin{array}{c}\text { Elongation break } \\
\left(\% m^{2}\right)\end{array}$ & $\begin{array}{l}\text { Elastic module } \\
\qquad\left(\mathrm{kg} / \mathrm{mm}^{2}\right)\end{array}$ & Strain \\
\hline F1 & $2.24 \pm 0.056$ & $12.02 \pm 0.24$ & $9.33 \pm 0.05$ & $0.24 \pm 0.05$ \\
\hline F2 & $2.64 \pm 0.024$ & $16.48 \pm 0.25$ & $7.33 \pm 0.02$ & $0.36 \pm 0.06$ \\
\hline F3 & $3.245 \pm 0.226$ & $15.02 \pm 0.28$ & $6.76 \pm 0.024$ & $0.48 \pm 0.04$ \\
\hline F4 & $2.60 \pm 0.035$ & $16.5 \pm 0.22$ & $7.22 \pm 0.032$ & $0.36 \pm 0.03$ \\
\hline F5 & $2.66 \pm 0.026$ & $16.57 \pm 0.26$ & $7.18 \pm 0.03$ & $0.37 \pm 0.05$ \\
\hline
\end{tabular}

Values represent Mean $\pm S D(n=3)$.

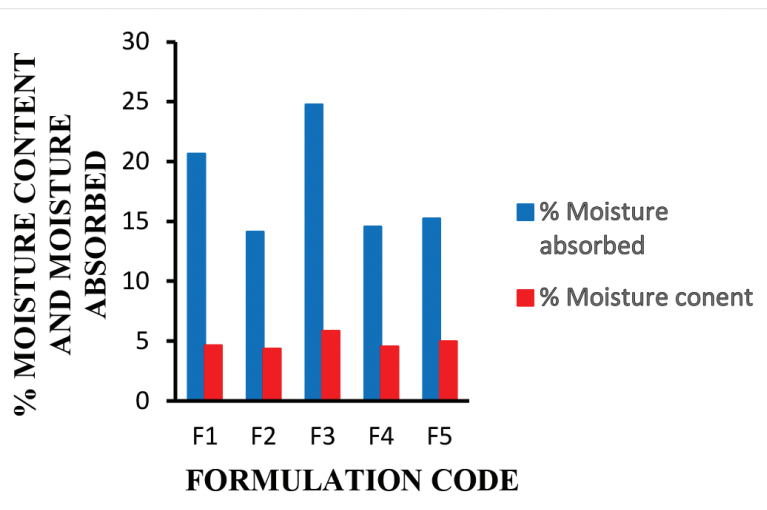

Figure 1: Moisture studies of transdermal patches

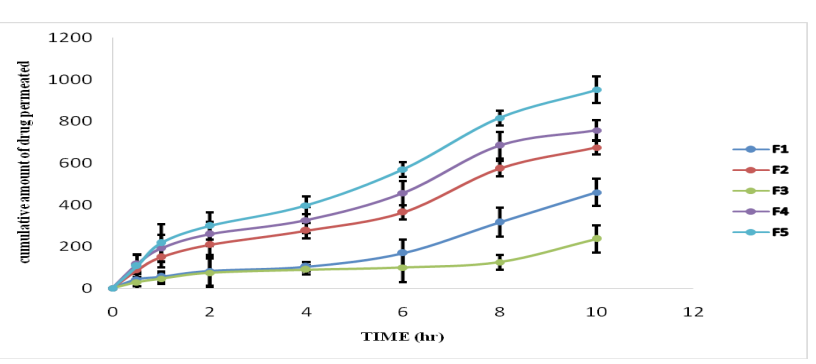

Figure 2: In vitro drug release studies of transdermal patches.
EM also increased but E/B values decreased. These results revealed that optimized formulations were found to be strong and flexible but not brittle. ${ }^{14}$

\section{In vitro drug release studies}

The drug release profile of prepared transdermal films are represented in Figure 2 and Table 4. The results of release studies showed that F2 formulation has higher drug release $673.774 \pm 32.65 \mu \mathrm{g}$ in $10 \mathrm{hrs}$ compared to F1 and F3. Hence, formulations containing permeation enhancers F4 and F5 showed higher drug release $756.14 \pm 48.36 \mu \mathrm{g}$ and $951.24 \pm 64.95 \mu \mathrm{g}$ in $10 \mathrm{hrs}$ respectively compared with formulation without permeation enhancers. From the results and graphs it is clear that the drug release was depends on polymer and permeation enhancer content. An increase in the content of polymer was associated with decrease in drug release rate. The in vitro release data of all formulations of patches well fitted into zero order equation, $\mathrm{R}^{2}$ values were between 0.882 to 0.9822 . Values of release exponent (n) in the range of 0.5828 to 0.741 revealed that release pattern was found to follow anomalous transport mechanism results showed in Table 5 .

\begin{tabular}{|c|c|c|c|c|c|}
\hline \multirow{2}{*}{ Time(hr) } & \multicolumn{5}{|c|}{ Cumulative amount of drug released $(\boldsymbol{\mu g})}$. \\
\cline { 2 - 6 } & $\mathbf{F 1}$ & $\mathbf{F 2}$ & $\mathbf{F 3}$ & $\mathbf{F 4}$ & F5 \\
\hline 0 & 0 & 0 & 0 & 0 & 0 \\
\hline 0.5 & $43.112 \pm 32.12$ & $86.274 \pm 29.91$ & $29.125 \pm 54.69$ & $115.32 \pm 45.25$ & $106.28 \pm 56.24$ \\
\hline 1 & $55.482 \pm 25.45$ & $149.34 \pm 48.98$ & $45.316 \pm 23.58$ & $191.23 \pm 64.23$ & $216.65 \pm 89.24$ \\
\hline 2 & $82.69 \pm 69.54$ & $209.068 \pm 49.98$ & $74.215 \pm 69.45$ & $259.32 \pm 58.42$ & $299.12 \pm 65.75$ \\
\hline 4 & $103.15 \pm 21.78$ & $276.388 \pm 37.14$ & $89.432 \pm 23.45$ & $326.54 \pm 62.14$ & $396.65 \pm 42.67$ \\
\hline 6 & $168.62 \pm 65.48$ & $364.379 \pm 34.32$ & $99.25 \pm 69.54$ & $456.12 \pm 58.74$ & $569.45 \pm 35.84$ \\
\hline 8 & $316.49 \pm 68.45$ & $573.815 \pm 37.22$ & $125.712 \pm 35.42$ & $684.65 \pm 63.21$ & $815.47 \pm 34.58$ \\
\hline 10 & $458.97 \pm 64.78$ & $673.774 \pm 32.65$ & $237.25 \pm 32.65$ & $756.14 \pm 48.36$ & $951.24 \pm 64.95$ \\
\hline
\end{tabular}

Values represent Mean $\pm S D(n=3)$. 


\section{Table 5: Drug release kinetics of transdermal patches}

\begin{tabular}{|c|c|c|c|c|c|}
\hline $\begin{array}{c}\text { Formulation } \\
\text { Parameter }\end{array}$ & F1 & F2 & F3 & F4 & F5 \\
\hline Zero order & 0.9281 & 0.9749 & 0.882 & 0.9703 & 0.9822 \\
\hline First order & 0.9863 & 0.9262 & 0.8902 & 0.9262 & 0.894 \\
\hline Higuchi & 0.8013 & 0.9336 & 0.829 & 0.949 & 0.9496 \\
\hline Peppas & 0.893 & 0.9706 & 0.9204 & 0.9695 & 0.9769 \\
\hline $\mathrm{n}$ value & 0.741 & 0.6425 & 0.5828 & 0.598 & 0.681 \\
\hline
\end{tabular}

$\mathrm{n}$ value signifies anomalous transport mechanism in case of all formulation

\begin{tabular}{|c|c|c|c|c|}
\hline \multirow{2}{*}{ Time (hrs.) } & \multicolumn{3}{|c|}{ Cumulative amount of drug permeated $(\boldsymbol{\mu g})}$. \\
\cline { 2 - 5 } & Drug solution(D) & F2 Ex vivo permeation studies of transdermal patches \\
\hline 0 & 0 & 0 & F4 & F5 \\
\hline 0.5 & $110.78 \pm 29.90$ & $33.33 \pm 23.25$ & $82.35 \pm 28.22$ & $44.607 \pm 24.01$ \\
\hline 1 & $202.69 \pm 48.09$ & $57.84 \pm 38.69$ & $139.21 \pm 45.02$ & $132.72 \pm 42.22$ \\
\hline 2 & $257.72 \pm 49.96$ & $83.45 \pm 37.77$ & $169.85 \pm 46.86$ & $164.09 \pm 40.21$ \\
\hline 4 & $312.13 \pm 37.14$ & $105.51 \pm 21.93$ & $218.38 \pm 35.34$ & $251.59 \pm 32.43$ \\
\hline 6 & $403.79 \pm 34.32$ & $174.26 \pm 32.14$ & $292.15 \pm 31.08$ & $364.09 \pm 28.98$ \\
\hline 8 & $590.5 \pm 27.22$ & $327.94 \pm 35.21$ & $394.85 \pm 28.98$ & $514.09 \pm 35.65$ \\
\hline 10 & $707.47 \pm 32.65$ & $467.89 \pm 28.31$ & $532.72 \pm 30.65$ & $650.36 \pm 29.6$ \\
\hline Flux $\left(\mu \mathrm{g} / \mathrm{cm}^{2} / \mathrm{hr}\right)$ & 18.756 & 12.936 & 16.578 & 20.462 \\
\hline
\end{tabular}

Values represent Mean $\pm S D(n=3)$.

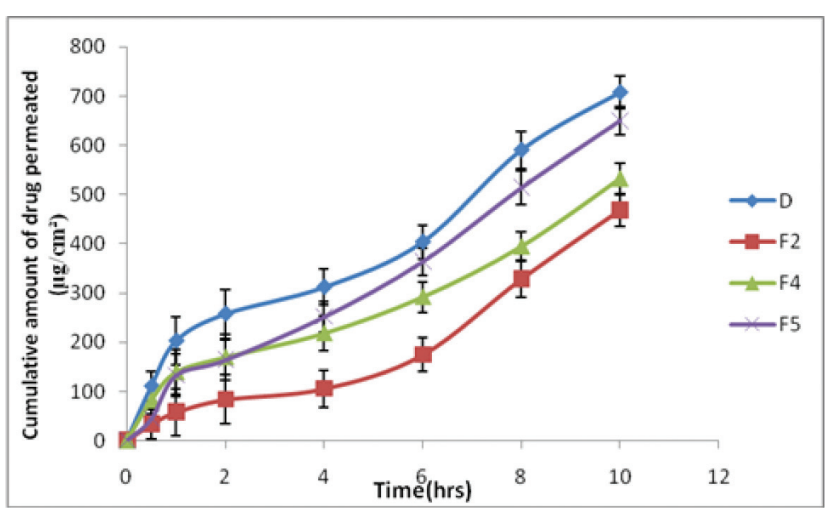

Figure 3: Ex vivo permeation studies of transdermal patches.

\section{Ex vivo permeation studies}

Ex vivo permeation studies were carried out for F2, F4, F5 formulation and drug solution. The results showed in Figure 3 and Table 6 reveals that F2 formulation has drug permeation467.89 $\pm 28.31 \mu \mathrm{g} / \mathrm{cm}^{2}$ and flux $12.936 \mu \mathrm{g} / \mathrm{cm}^{2} / \mathrm{hr}$ in $10 \mathrm{hrs}$. Earlier research studies revealed that menthol and eucalyptus oil were used as permeation enhancers. To increase the drug permeation, permeation enhancer (Menthol F4 and Eucalyptus oil F5) in the concentration of $5 \% \mathrm{v} / \mathrm{w}$ was added to $\mathrm{F} 2$ formulation which showed a result of drug permeation, flux and enhancement ratio $532.72 \pm 30.65 \mu \mathrm{g} / \mathrm{cm}^{2}, 650.36 \pm$ $29.6 \mu \mathrm{g} / \mathrm{cm}^{2}, 16.578 \mu \mathrm{g} / \mathrm{cm}^{2} / \mathrm{hr}, 20.462 \mu \mathrm{g} / \mathrm{cm}^{2} / \mathrm{hr}$ and $1.28,1.58$ respectively. Hence, with the use of permeation enhancer showed a good result in increase of drug permeation. Plotting the cumulative amount drug permeated per square centimeter of the patches through the rat abdominal skin against time in minutes showed that, the profile of drug permeation might follow zero order kinetics as it was proved by correlation coefficients 0.95 to 0.99 , better fit than first order $\left(r^{2}=0.852\right.$ to $0.966)$ and korsmeyer peppas model $\left(\mathrm{r}^{2} 0.925\right.$ to 0.963 and $n$ values 0.55 to 0.806 ). The $r^{2}$ and $n$ values reveal that the permeation of Domperidone maleate from the transdermal films followed zero order and through anomalous mechanism. The required flux for domperidone maleate was approximately $88.28 \mu \mathrm{g} / \mathrm{cm}^{2} / \mathrm{hr}$ and flux obtained by optimized formulation F5 was $20.462 \mu \mathrm{g} / \mathrm{cm}^{2} / \mathrm{hr}$. in order to reach the required flux, the flux area has to be increased up to $17.26 \mathrm{~cm}^{2}$. Finally cumulative percentage of drug permeated through the rat skin was correlated against cumulative percentage of drug released using in vitro release test for optimized formulation F5, Figure 4 shows the relationship between the percentage of domperidone maleate released in vitro and percentage of drug permeated ex vivo. The straight 


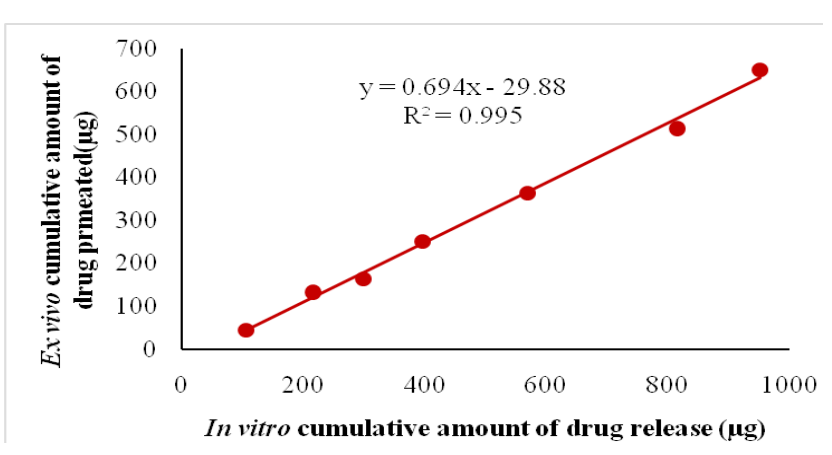

Figure 4: In vitro and Ex vivo correlation between cumulative amount drug released In vitro and amount drug permeated Ex vivo of optimized Domperidone maleate transdermal patch (F5).

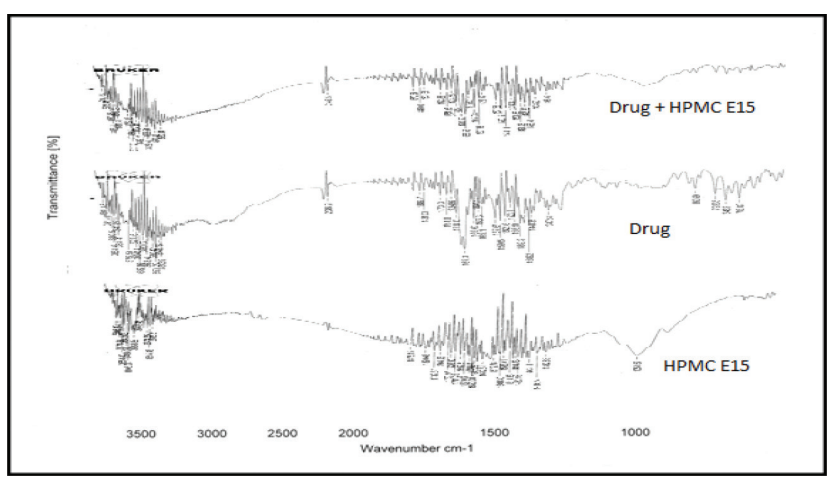

Figure 5: FTIR spectra of pure drug, polymer HPMC E15, and drug+ polymer HPMC E15

line and the high correlation coefficient of 0.995 proved the good correlation between in vitro drug release and Ex vivo drug permeation studies. Hence by considering the complete difference in the test conditions of in vitro and Ex vivo release studies, the high correlation and coincidence of in-vitro and Ex vivo release profiles, it can be concluded that such a transdermal patches could be a useful carrier in transdermal drug delivery systems.

\section{Drug- polymer interaction studies}

The FTIR spectral analysis of Domperidone maleate alone showed that the principal peaks were observed at wave numbers of $3530.06 \mathrm{~cm}^{-1}$ (N-H stretching), $2346.21 \mathrm{~cm}^{-1}$ (asymmetric C-H stretching), $1846.57 \mathrm{~cm}^{-1}$ $(\mathrm{N}=\mathrm{C}$ stretching $)$ and $1715.31 \mathrm{~cm}^{-1}, 1694.22 \mathrm{~cm}^{-1}(\mathrm{C}=\mathrm{O}$ stretching). Some other peaks which were observed at $1147.18 \mathrm{~cm}^{-1}$ and $1062.18 \mathrm{~cm}^{-1}$. The HPMC E15 FTIR spectrum presented a profile without distinctly high peaks. The FTIR spectra of the physical mixture of Domperidone maleate and HPMC E15 showed approximate superimposition of the drug and HPMC E15. These results suggest that there is no interaction between the drug and polymers used in the present study. The FTIR profiles were shown Figure 5.

\section{CONCLUSION}

The present study showed that domperidone maleate patch containing HPMC E15 in the ratio of 1:12.5 with $15 \% \mathrm{v} / \mathrm{w}$ of PEG-400, achieved the desired objectives of TDDS, such as overcoming of first pass effect, extended release and frequency of administration may serve as better system for transdermal delivery. The polymeric films containing domperidone maleate were prepared and evaluated for physicochemical, in vitro drug release and permeation characteristics. The formulations containing HPMC E15 and permeation enhancers (eucalyptus oil $5 \% \mathrm{v} / \mathrm{w})$ were found to higher flux $\left(20.462 \mu \mathrm{g} / \mathrm{cm}^{2} / \mathrm{hrs}\right.$.). Good in vitro and ex vivo correlation for optimized transdermal patch demonstrates the validity of the release test conducted. The transdermal patches of domperidone maleate with required flux could be prepared with suitable mechanical properties, further studies are recommended to find their therapeutic utility in humans by pharmacokinetic and pharmacodynamics studies.

\section{ACKNOWLEDGEMENT}

Authors are thankful to Merk limited, Mumbai, India for providing gift sample of Domperidone Maleate.

\section{CONFLICT OF INTEREST}

There is no conflict of interest.

\section{ABRREVIATIONS USED}

HPMC E15- Hydroxy Propyl Methyl Cellulose E15, DCM- Dichloro methane, PEG- Poly Ethylene Glycols, TDDS- Transdermal Drug Delivery System.

\section{REFERENCES}

1. Chien Y.W. Novel Drug Delivery Systems. Drugs and Pharmaceutical Sciences, 2nd Edition. Volume-50, Marcel Dekker, Inc.

2. Chien Y. W. Transdermal Therapeutic systems. Robinson Joseph R, Lee Vincent HL. Editors. Controlled Drug Delivery: Fundamentals \& Applications, New York: Marcel Dekker; 1987. p. 523. https://doi.org/10.1201/b14193-15.

3. Barry B.W. Dermatological formulation, New York: Mercel Dekker; 1983.p. 225-8.

4. Barry B. Transdermal Drug Delivery. Aulton M E editor. Pharmaceutics: The Science of Dosage Form Design, Churchill Livingston: 2002. p. 499-533.

5. Robinson J.R, Lee V.H. Controlled drug delivery fundamentals and applications, New York: Marcel Dekker: 1987. p. 52-5. https://doi.org/10.1201/ b14193.

6. Sweetman S.C. Martindale. The complete drug reference, London: Pharmaceutical Press: 2007. p. 1556-7.

7. Finnin BC, Morgan TM. Transdermal penetration enhancers: applications, limitations, and potential. Journal of pharmaceutical sciences. 1999;88(10):955-8. https://doi.org/10.1021/js990154g.

8. El-Kattan AF, Asbill CS, Michniak BB. The effect of terpene enhancer lipophilicity on the percutaneous permeation of hydrocortisone formulated in 
HPMC gel systems. International journal of pharmaceutics. 2000;198(2):179-89. https://doi.org/10.1016/S0378-5173(00)00330-6.

9. Williams AC, Barry BW. Terpenes and the lipid-protein-partitioning theory of skin penetration enhancement. Pharmaceutical research. 1991;8(1):17-24. https://doi.org/10.1023/A:1015813803205.

10. Pillai $O$, Panchagnula R. Transdermal iontophoresis of insulin: V. Effect of terpenes. Journal of controlled release. 2003;88(2):287-96.https://doi. org/10.1016/S0168-3659(03)00065-8

11. Moghimi H.R, Williams A.C, Barry B.W. A lamellar matrix model for stratum corneum intercellular lipids. Effect of terpenes penetration enhancers on the structure and thermal behavior of the matrix. Int J Pharm 1997; 146: 41-54. https://doi.org/10.1016/S0378-5173(96)04766-7.

12. Lee PJ, Ahmad N, Langer R, Mitragotri S, Shastri VP. Evaluation of chemical enhancers in the transdermal delivery of lidocaine. International journal of pharmaceutics. 2006;308(1):33-9. https://doi.org/10.1016/j. ijpharm.2005.10.027; PMid:16321488.

13. Gao S, Singh J. In vitro percutaneous absorption enhancement of a lipophilic drug tamoxifen by terpenes. Journal of controlled release. 1998;51(2):193-9. https://doi.org/10.1016/S0168-3659(97)00168-5.

14. Gannu R, Vishnu YV, Kishan V, Rao YM. Development of carvedilol transdermal patches: evaluation of physicochemical, Ex vivo and mechanical properties. PDA Journal of Pharmaceutical Science and Technology. 2008;62(6):391-401. PMid:19634343.
15. Mandal SC, Bhattacharyya M, Ghosal SK. In-vitro Release and Permeation Kinetics of Pentazociwe From Matrix-Dispersion Type Trawsdwul Drug Delivery Systw. Drug development and industrial pharmacy. 1994;20(11):1933-41. https://doi.org/10.3109/03639049409050220.

16. Gupta JR, Irchhiaya R, Garud N, Tripathi P, Dubey P, Patel JR. Formulation and evaluation of matrix type transdermal patches of Glibenclamide. Int $\mathrm{J}$ Pharm Sci Drug Res. 2009;1(1):46-50.

17. Kusum Devi V, Saisivam S, Maria GR, Deepti PU. Design and evaluation of matrix diffusion controlled transdermal patches of verapamil hydrochloride. Drug development and industrial pharmacy. 2003;29(5):495-503. https://doi. org/10.1081/DDC-120018638; PMid:12779279

18. Gannu R, Vamshi Vishnu Y, Kishan V, Madhusudan Rao Y. Development of nitrendipine transdermal patches: in vitro and Ex vivo characterization. Current Drug Delivery. 2007;4(1):69-76. https://doi. org/10.2174/156720107779314767; PMid:17269919.

19. Friend DR. In vitro skin permeation techniques. Journal of Controlled Release. 1992;18(3):235-48. https://doi.org/10.1016/0168-3659(92)90169-R.

20. Franz TJ. Percutaneous absorption. On the relevance of in vitro data. Journal of Investigative Dermatology. 1975;64(3):190-5. https://doi.org/10.1111/15231747.ep12533356.

21. Aulton ME, Abdul-Razzak MH, Hogan JE. The mechanical properties of hydroxypropylmethylcellulose films derived from aqueous systems Part 1: the influence of plasticisers. Drug Development and Industrial Pharmacy. 1981;7(6):649-68. https://doi.org/10.3109/03639048109055689.

\section{SUMMARY}

- Domperidone maleate matrix type transdermal patches were prepared using different ratios of HPMC E15 polymer and PEG-400 as a plasticizer.

- The formulation containing drug and polymer ratio 1 : 12.5 , plasticizer $15 \% \mathrm{v} / \mathrm{w}$ and permeation enhancer $5 \% \mathrm{w} / \mathrm{w}$ showed higher flux

\section{About Authors}

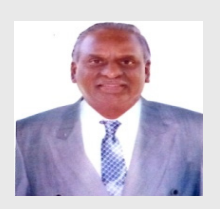

Prof. (Dr.). Yamsani Madhusudan Rao: Director, Vaagdevi Group of colleges, Warangal (T.S), India. He has five patents to his credit and has also authored several publications which include eight books related to Pharmaceutical Technology sector. He is guiding several M.Pharm and Ph D candidates for research projects sponsored by various government agencies. He has delivered several invited lecturers.

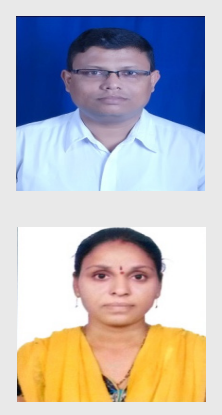

Dr. Sunit Kumar Sahoo: Lecturer in pharmaceutics, University Department of Pharmaceutical Sciences, Utkal University, Vanivihar, Bhubaneswar, Orissa-75100. He hasthirteen years of teaching and twelve yearsof researchexperience, he has published two books and sixty four publications of national and international repute. He has participated/ presented 65 national and international conferences/seminars/ workshops.

Suddala Shirisha: Research scholar in University Department of Pharmaceutical Sciences, Utkal University, Vanivihar. Bhubaneswar, Orissa-75100.

Cite this article: Shirisha S, Joshi G, Sahoo SK, Rao YM. Preparation and Evaluation of Matrix Type Transdermal Patches of Domperidone Maleate: in vitro and ex vivo Characterization. Indian $\mathrm{J}$ of Pharmaceutical Education and Research. 2017;51(4):517-24. 